Põlluste, K., Kosunen, E., Koskela, T., Mattila, K.J., Schäfer, W.L.A., Boerma, W.G.W., Lember, M. Primary health care in transition: variations in service profiles of general practitioners in Estonia and in Finland between 1993 and 2012. Health Policy: 2018

Postprint version :

Journal website $\quad:$ https://www.sciencedirect.com/science/article/pii/S0168851018305608 ?via\%3Dihub

Pubmed link $\quad:$ https://www.ncbi.nlm.nih.gov/pubmed/30322719

DOI

: $\quad$ 10.1016/j.healthpol.2018.10.002

This is a Nivel certified Post Print, more info at nivel.nl

\title{
Primary health care in transition: Variations in service profiles of general practitioners in Estonia and in Finland between 1993 and 2012
}

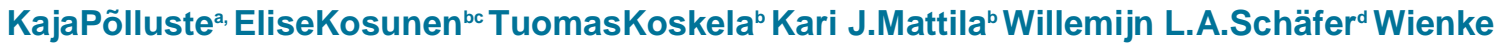 \\ G.W.Boermad ${ }^{d}$ MargusLember ${ }^{\text {ae }}$
}

\footnotetext{
a University of Tartu, Institute of Clinical Medicine, Department of Internal Medicine, Tartu, Estonia ${ }^{b}$ University of Tampere, School of Medicine, Department of General Practice, Tampere, Finland

${ }^{c}$ Pirkanmaa Hospital District, Centre of General Practice, Finland

${ }^{d}$ NIVEL - the Netherlands Institute for Health Services Research, Utrecht, the Netherlands

${ }^{\mathrm{e}}$ Tartu University Hospital, Internal Medicine Clinic, Tartu, Estonia
}

Highlights

In 1993-2012 services profiles of GPs changed in Estonia and in Finland.

- Partly opposite changes decreased the variation of service profiles between the countries.

- Existing variations might result from organisational aspects, staff training and patients' preferences.

\begin{abstract}
Introduction: Since the early 1990s, the Estonian and Finnish health systems have undergone various changes which are expected to have impacted the type and range of services provided by general practitioners (GPs).

Objective: To compare GP services between Estonia and Finland in 1993 and 2012 and draw a parallel with transformations occurred in the health systems of both countries during these two decades.

Methods: Data were collected through surveys among 129 and 288 GPs from Estonia and Finland in 2012 and 139 Estonian and 239 Finnish GPs in 1993. Descriptive statistics were used to compare between countries and years.
\end{abstract}


Põlluste, K., Kosunen, E., Koskela, T., Mattila, K.J., Schäfer, W.L.A., Boerma, W.G.W., Lember, M. Primary health care in transition: variations in service profiles of general practitioners in Estonia and in Finland between 1993 and 2012. Health Policy: 2018

Results: Between 1993 and 2012, the number of working hours per week and consultations per day increased in Estonia and decreased in Finland. In 2012, GPs in were more often the first contact for psychosocial and women's and children's in Estonia, whereas this decreased in Finland. The frequency of treating acute patients mostly decreased in both countries. We observed a decrease in medical procedures in Finland and an increase in Estonia. Finnish GPs still conducted more procedures in 2012. Conclusion: Due to partly opposite changes, the services provided by Finnish and Estonian GPs became more similar. Still, there are large differences in services provided, possibly arising from differences in the organisation of health services, the training of doctors and patients' preferences.

\section{Introduction}

Estonia and Finland are neighbouring countries situated on the southern and northern coasts of Gulf of Finland. Both countries have been under foreign dominance before becoming independent republics - Finland in 1917 and Estonia in 1918. Until the Second World War, the two countries collaborated in many fields of society including trade, economy, culture, and education. After the war, the countries remained on opposite sides of the 'iron curtain' which led to differences in the development of health care and the role of primary care (PC). However, after Estonia regained its independency in 1991 contacts between the countries were reinforced. Collaboration in all areas, including health care, has become even stronger since Estonia became a member of European Union in 2004.

Today, the development and sustainment of strong primary care is prioritized in many European countries. As suggested in a recent study, both Estonia and Finland are considered to be countries with relatively strong PC [1]. However, due to the changes in the whole society the transition in Estonian PC has been very rapid in the past decades [2] and considerably more drastic than in Finland. Because of a more stable development of the society during the second half of the $20^{\text {th }}$ century, Finland can be used as reference point for Estonia. A broad range of services provided by GPs is an indicator for a strong position of the PC provider in the health system. Previous studies found large differences in primary care services between Eastern and Western Europe [3,4]. Schäfer et al $(2016)$ found that between 1993 and 2012 the variety of services provided by GPs increased more in former communist countries than in Western European countries; the changes in the range of services provided were found to be associated with national conditions, including the growth of health care expenditures [4]. Thus, a comparison of GP services in Estonia and Finland provides an overview of the development of PC in those two countries and illustrates the differences in the development of PC between Western and Eastern Europe since the beginning of 1990s.

\section{Background}

\section{Development of PC systems in Estonia and in Finland until 1990s}

In the first half of 20th century the provision of health services in both countries was decentralised, being mostly the responsibility of municipalities [5,6]. Later, the progress of Estonian and Finnish health care was rather different which resulted in different organizational models in PC.

In Finland, the role of municipalities in the organization of PC services was continually strengthened by introducing new legislation after the Second World War. Every municipality had to contract general practitioners (GPs), midwives and public health nurses. They were expected to handle a wide variety of health problems as the overall number of doctors was small [5]. At the same time, in Estonian the 
Põlluste, K., Kosunen, E., Koskela, T., Mattila, K.J., Schäfer, W.L.A., Boerma, W.G.W., Lember, M. Primary health care in transition: variations in service profiles of general practitioners in Estonia and in Finland between 1993 and 2012. Health Policy: 2018

Soviet Semashko health system was introduced. Under this system, health care was funded through the state budget and managed by the government through central planning. The health care delivery system focused mainly on curative care and development of an excessive hospital network [6]. PC was fragmented, as the services were provided by district doctors and paediatricians in separate polyclinics for adults, children and women, as well as by specialists in specialized dispensaries [6]. Thus, compared to their Finnish colleagues, the services provided by the Estonian PC doctors were more limited, as specialised doctors were directly accessible (e.g. district doctors for adults and district paediatricians) and, consequently, certain problems almost never reached the PC doctor [7]. In the 1950s and 1960s, in Finland most of the public expenditure on health care was allocated to hospitals and only $10 \%$ of total public health care expenditure was spent on PC. Therefore, the supply of outpatient services and PC was insufficient [5]. A new system of PC in Finland was established through the Primary Health Care Act in 1972. After enforcement of this act huge investments were made in Finland to promote PC in the 1970s and 1980s, with the goal of providing a large scope of medical and preventive services by GPs in municipality health centres [8]. This was supported by GP specialist training, which started in 1970 and the goals and the contents were clarified in 1987 [9]. Unlike the Finnish GPs, most Estonian PC doctors were trained as internists or paediatricians [7]. These two aspects - different principles implemented in the organization of PC and in training of PC doctors - led to the considerable variations in services provided by Estonian and Finnish PC doctors as demonstrated in a study by Lember et al (1993): the number of procedures carried out by the PC doctors themselves was remarkably higher in Finland than in Estonia, and Finnish GPs also handled a larger variety of health problems. Still, GPs' involvement in managing certain patient groups including elderly patients and patients with acute or psychosocial problems was rather similar in both countries [7].

Progress of Estonian and Finnish PC since 1991

Since the beginning of $90 \mathrm{~s}$ the demographic situation has changed and this change paralleled the changes in the health systems of both countries (Table 1) [[10], [11], [12]].

[table 1]

The transition and reorganisation of PC in Estonia started at the beginning of the 1990s after the country regained its independence. Estonia aimed to build up a system that could provide continuous and comprehensive health care for individuals of all ages and both sexes. These aims were to be facilitated by the creation of a list system for GPs, meaning that all people had to list with a personal GP, as well as a partial gate-keeping system (with direct access to some specialists, e.g. a psychiatrist, ophthalmologist or gynaecologist) and thereby handling most of population's health problems within PC. Consequently, the first step in the reorganisation of PC in Estonia was the re-training of practicing PC doctors, which started in 1991 and took until 2004; the residency training in family medicine (FM) started in 1993 [[13], [14], [15], [16]]. Since 2004, all physicians working in PC as GPs have been trained in FM [14]. In this process, the Estonian PC doctors closely collaborated with their colleagues from the neighbouring countries, including Finland. Currently, the residency training in Estonia and in Finland conforms to the common principles accepted in European Union [14,16].

The next step was the implementation of legislative framework for PC. In 1997, a combined payment system for GPs, a defined package of services provided by GPs, and the legal status of GPs as independent contractors were defined and introduced in Estonia [15]. Today, PC services are provided by GPs who are predominantly private practitioners contracted by the public health insurance. All GPs are required to work with at least one practice nurse. Moreover, the number of office hours of the GP and nurse are specified by the legislative acts [15]. About half of the GPs have solo practices. The solo practice model, including one GP and a practice nurse, is most common in rural areas. In urban areas, 
Põlluste, K., Kosunen, E., Koskela, T., Mattila, K.J., Schäfer, W.L.A., Boerma, W.G.W., Lember, M. Primary health care in transition: variations in service profiles of general practitioners in Estonia and in Finland between 1993 and 2012. Health Policy: 2018

most of the GPs work in the same building with other GPs or specialists. All of them have a personal patient list (with the size of $1600 \pm 400$ patients) and individual contracts with public health insurance. The GPs are paid through a combination of capitation payments, fee-for-service, basic allowance, quality bonus payments and other remuneration types which form the budget for the practices which supports the FM model $[6,15]$. Further evaluations of Estonian PC have demonstrated considerably high patient satisfaction and acceptability of the new system, an increased comprehensiveness of care [[17], [18], [19]], improved equipment of PC doctors [20], and an increase in the number of trained GPs [14]. The results of a study from 1997 showed that $95 \%$ of the newly trained GPs were satisfied, and that a well organized practice, high quality of equipment, and the opportunity to learn new things were the most valued aspects of the work [21]. Since the beginning of $90 \mathrm{~s}$, the number of out-patient contacts has not increased significantly (Table 1), however, about half of all out-patient visits are now made to the GPs [15].

Compared to Estonia, the changes in Finnish PC have been less fundamental. Currently, around a quarter of all physicians have specialist training in general practice [22]. During the last ten years, the focus in Finland has been on educating GP trainers to enable systematic supervision for specialist trainees. Unlike Estonia, the PC services in Finland are mostly provided by GPs working in municipal multidisciplinary health centres. Moreover, a combination of payment systems for GPs is used; most physicians receive a monthly salary with some extra fee-for-service payments for selected timeconsuming services or minor medical procedures. Another group of physicians is paid through a combination of a basic salary, capitation payment, and fee-for-service payment for visits [5]. Since the beginning of 1990s the total number of physicians in Finland more than doubled (Table 1), but the number of positions in public primary health care increased only marginally [22], despite increasing workload. At the same time, service provision through the private sector increased remarkably, particularly in occupational health care. The Finnish Social Insurance Institution reimburses employers for the costs of preventive occupational health care (obligatory), and also the costs of diagnostic and treatment of diseases at primary health care level (optional). Widening of the optional part of occupational health care has drawn experienced GPs from health centres. It has also affected profile of the service users, as working age patients have moved away from health centres to occupational health care, especially in big cities [23]. In the 2000s health centres suffered from a shortage of physicians [24]. The proportion of young doctors who are carrying out their mandatory PC service (9 months in all specialist training programmes) with short contracts is high in health centres. Unlike Estonia, accessibility and continuity of care, as well as patient satisfaction, declined during the past decade [25]. At present, there is no evidence on how these changes affected the services provided Finnish GPs.

In this study we will describe the development of GP services provided in two neighbouring countries where the PC systems were developed in an entirely different context. Considering the developments and current evidence, we hypothesize that in both countries the services provided have changed compared since the early 90 sand that the breadth of service profile expanded in Estonia. Specifically, we will assess the changes in the workload of the GPs, their role as a first contact in health problems and their involvement in medical procedures between 1993 and 2012.

\section{Methods}

The data were collected within the framework of the European GP Task Profile study in 1993 [3] and QUALICOPC (Quality and Costs of Primary Care in Europe) study in 2012. The European GP Task Profile study was based on a questionnaire completed by samples of GPs in each of 30 countries of Europe [3]. The QUALICOPC study covered 26 European Union Member States, Switzerland, Turkey, Iceland, Norway, and Macedonia, as well as Australia, Canada, and New Zealand. 
Põlluste, K., Kosunen, E., Koskela, T., Mattila, K.J., Schäfer, W.L.A., Boerma, W.G.W., Lember, M. Primary health care in transition: variations in service profiles of general practitioners in Estonia and in Finland between 1993 and 2012. Health Policy: 2018

In 1993, the study included random samples of PC doctors from Estonia and GPs from Finland. The structured pre-coded questionnaires were mailed with one reminder to those included in the samples; the response rate was 62\% (139 respondents) in Estonia and 42\% (239 respondents) in Finland. Details of the sampling procedures and data collection process are described elsewhere [7].

In 2012, the QUALICOPC study protocol aimed to reach 220 GPs in each country, including only one GP per practice. In Estonia, the invitation to participate in the study was sent by e-mail to all 802 practicing GPs in the country as all of them had a valid e-mail address for professional communication. The invitation included the link to the web based survey and personal identification code. After two reminders the responses from 129 GPs were received (response rate: 16.1\%). The age and gender structure of the respondents corresponded to that of the entire sample of Estonian GPs. The respondent sample covered all regions; however, the western and eastern counties of Estonia were underrepresented and southern counties overrepresented.

In Finland, a random sample ( $n=700$ ) of GPs working in municipal health centres was drawn from the register of the Finnish Medical Association. After one reminder, the response rate was still low, and thus data collection continued by sending the invitation to 206 GPs who were registered in GP specialist training at the University of Tampere. At this point, the total response rate was $24.7 \%$. In the third stage, the directors of health centres in Tampere University Hospital District were asked to recruit 1-5 doctors to participate, depending on the size of the population in their health centre area. Altogether, we received 288 completed questionnaires. The sample of respondents covered both urban and rural areas, but western Finland is overrepresented, due to the additional data collection methods. Neither the Estonian or Finnish GPs received a monetary incentive for participation in the study. In Estonia, the participating GPs did receive credits for personal certification and accreditation of their practice. In both countries, a letter of recommendation from professional societies in recruitment of study participants was used.

The GP questionnaire mainly focused on the practice organization and care processes, whereby a set of questions on GP services from 1993 were repeated in 2012 [26,27]. In this study we describe and compare the services provided by GPs in Estonia and in Finland by using the following indicators. Firstly, we compared working hours and patient contacts of GPs. Secondly, we evaluated the involvement of GPs in some minor surgical and investigative procedures. Thirdly, a series of health problems in various patient groups (children, women, and elderly patients, patients with acute or psychosocial problems) were evaluated. The GPs were asked to indicate their involvement in these services according to a pre-coded scale (almost always, usually, occasionally, seldom, or never). Descriptive analyses were performed using the SPSS statistical package (version 24.0). To estimate the change in services provided, we compared the data from 2012 to the data from 1993. Differences between 1993 and 2012 and those between the countries were tested through conducting t-tests. We also assessed if GP and GP practice characteristics (age, practice location in urban or rural area, or distance from the nearest hospital) were associated with the differences in service profile. The level of statistical significance was set at $p<0.05$.

\section{Results}

\section{Sample description and practice information}

The large majority of the Estonian respondents were female doctors (91\%); however, compared to the previous study, the proportion of male GPs increased from $7 \%$ to $9 \%$. At the same time, in Finland the proportion of female doctors was 72\%, which is considerably higher than in 1993 (54\%). In both years, the proportion of female GPs in Estonia was significantly higher than in Finland. The mean age $( \pm S D)$ of Estonian and Finnish respondents was $50.8 \pm 7.7$ and $45 \pm 12$ years, respectively, indicating a higher average age of the Estonian respondents. Also, in 1993, the average age of the Estonian GPs was higher than the Finnish GPs. In 1993, more Estonian GPs reported to work in rural areas (33.7\% vs 4.2\% 
Põlluste, K., Kosunen, E., Koskela, T., Mattila, K.J., Schäfer, W.L.A., Boerma, W.G.W., Lember, M. Primary health care in transition: variations in service profiles of general practitioners in Estonia and in Finland between 1993 and 2012. Health Policy: 2018

in Finland, $p<0.001)$, whereas in 2012 the sample contained more Finnish GPs from rural areas $(20.4 \%$ vs $9.3 \%$ in Estonia, $\mathrm{p}<0.001$ ). Additionally, in both years the Finnish GP practices were located further away from hospitals.

In Estonia, the number of consultations per day, including phone and e-mail consultations, increased and the regular working hours did not increase significantly. The number of home visits decreased notably, reaching the same level as it was in Finland in 1993. In Finland, the number of regular working hours and consultations per day decreased, and the number of phone consultations increased slightly compared to 1993 . Thus, in 2012, the number of regular working hours as well as the number of consultations was higher in Estonia; however, consultation time was longer in Finland. Compared to 1993, the changes in the work of GPs in Estonia and in Finland were in opposite directions (Table 2).

[table 2]

First contact with health problems

Compared to 1993, the frequency of handling the health problems of women and children in Estonia increased $(p<0.001)$ and by 2012 reached the same level as it was in Finland in 1993. At the same time, in Finland the proportion of GPs being the first contact for those patients demonstrated a decrease ( $p<0.001$ ) (Fig. 1). GP involvement in the management of some psychosocial problems demonstrated a similar tendency. Greatest differences were found in GPs treating acute surgical problems, such as a sprained ankle. In Estonia, the percentage of GPs treating this health problem increased $(p<0.01)$, while in Finland the percentage decreased $(p<0.001)$. The change in management of other acute problems was quite similar in both countries: in 2012 doctors in both countries were less frequent the first contact for patients with pain in the chest and paralysis than in $1993(p<0.001)$.

\section{[figure 1]}

\section{Medical procedures}

Estonian GPs became more often performed cryotherapy or the excision of warts, removal of sebaceous cysts from the scalp, resection of ingrown toenails, and setting up intravenous infusions. Still, as in 1993, the percentage of physicians who reported performing all procedures listed in Fig. 2 themselves were higher in Finland than in Estonia $(p<0.001)$. The figures mostly remained at the same level as before in Finland, but a more pronounced decrease $(p<0.001)$ was found in procedures related to acute care, such as strapping an ankle or setting up intravenous infusions (Fig. 2).

[figure 2]

\section{Discussion}

To our knowledge, this is the first study reporting on changes in the services of PC doctors between 1993 and 2012 in two neighbouring countries with demographical and historical commonalities, but also big differences in historical background and health system developments. The present health care organization models in Estonia and Finland aim to incentivise GPs, together with other PC staff, to provide a comprehensive set of health services. In 1993, the comparison of GP services demonstrated a large variation between Estonia and Finland. In 2012 the type of services provided by GPs in Estonia 
Põlluste, K., Kosunen, E., Koskela, T., Mattila, K.J., Schäfer, W.L.A., Boerma, W.G.W., Lember, M. Primary health care in transition: variations in service profiles of general practitioners in Estonia and in Finland between 1993 and 2012. Health Policy: 2018

and Finland were more similar than 20 years ago. The main results of the study are summarised as follows:

$1 \quad$ Between 1993 and 2012 the number of working hours per week and consultations per day increased in Estonia and decreased in Finland;

$2 \quad$ In 2012, GPs in were more often the first contact for psychosocial and women's and children's in Estonia, whereas this decreased in Finland; the frequency of treating acute patients mostly decreased in both countries;

3 e observed a decrease in medical procedures in Finland and an increase in Estonia. Finnish GPs still conducted more procedures in 2012.

\section{Workload and number of consultations}

Compared to 1993, the number of consultations per day and the number of phone consultations in Estonia have increased; additionally, patients now have the opportunity to also consult their GP by email. At the same time, in Finland, the average regular working hours decreased compared to 1993, as well the number of consultations per day. Meanwhile, the length of consultation time at Finnish GP practices increased significantly, but did not change in Estonia.

In Estonia, an increased number of face-to-face consultations may refer to increased acceptability of the GP as a first contact for health problems, which was demonstrated in previous studies [17,18], but it also may be associated with more limited access to specialist care [19] due to gate-keeping system introduced in 1997 as well with the decreased use of inpatient care. Between 1993 and 2012 the total number of outpatient consultations per person has not changed, but the proportion of visits to the GPs has been increased [15] as GPs have taken over a number of patients previously treated by the specialists, e.g. paediatricians, gynaecologists, psychiatrists.

In Finland, working on a part-time basis is common nowadays, which was not the case in 1993. As a consequence of the shortage of physicians in the early 2000s, health centres have increased the role of nurses in handling follow-up of chronic diseases as well as minor complaints. Concurrently, hospitals have transferred care of chronically ill patients from their out-patient clinics to health centres.

Moreover, administrative and societal obligations have increased the GPs' workload.

The number of home visits has decreased in both countries. Under the Semashko system, home visits were seen as an essential element of a district doctor's work [7]. Therefore, in 1993 home visits were remarkably more frequent in Estonia than in Finland. However, the increasing availability of telephone and e-mail consultations in Estonia have made it possible to solve some health problems without seeing the doctor and are likely to have replaced some of the home visits. From the physician's point of view the home visits are time-consuming and by handling more contacts in the office GPs will save them time. Moreover, since 2002 there is a fee for home visits, whereas visits to the GP's office are covered. In 1993, the number of home visits in Finland was already very low compared to Estonia. As patients have been mostly encouraged to visit doctors at health centres [7], the proportion of GPs making home visits has decreased even further.

\section{GPs as a first contact to different health problems}

Compared to 1993, the GP's role as a first contact to health care has been increased in Estonia and decreased in Finland. First of all, Estonian GPs have become more often treat women's and children's health problems. Previously, these health problems were predominantly the domain of paediatricians and gynaecologists. This change is clearly related to the changes in health system as well to the changes in medical education [[13], [14], [15], [16], [17]]. The same trend was demonstrated in some other countries with major PC reforms including Lithuania [28] and Turkey [29]. At the same time, the involvement of Finnish GPs in handling the problems of women and children between 1993 and 2012 decreased. One explanation for this may be the increased use of private specialist services among women as well increased private insurances for small children. 
Põlluste, K., Kosunen, E., Koskela, T., Mattila, K.J., Schäfer, W.L.A., Boerma, W.G.W., Lember, M. Primary health care in transition: variations in service profiles of general practitioners in Estonia and in Finland between 1993 and 2012. Health Policy: 2018

Also, GPs' role as the doctor of first contact care for psychological problems showed an increase in Estonia, but the percentage of GPs handling these problems is still lower than in Finland. An explanation for this difference is that in Estonia patients can visit the psychiatrist without a referral from the GP, while Finnish health centre physicians are instructed to handle mild mental disorders themselves. Another reason might be related to GPs' knowledge and skills around psychological and mental health problems. As previously found, Estonian GPs were willing to manage patients with depression; however, most them felt that they needed additional training [30].

In general, Estonian GPs became less involved in managing acute problems. One reason can be the increased workload of GPs, which has brought about prolonged waiting times for patients. For example, the proportion of patients admitted on the same day when requested decreased from $59 \%$ in 1998 to $25 \%$ in 2006 [17,19]. Health problems such as acute chest or stomach pain mostly require immediate intervention, and if the GP is not available the patients are likely to call an ambulance or visit a hospital emergency department (ED). A previous study found that lower accessibility to the GP increased the probability of using ambulance services by 2.5 times [31]. Furthermore, in Estonia the out-of-hours services are not stipulated in the GP contract. Therefore, after-hours services for patients with acute health problems are provided by the hospital EDs and/or by ambulance service [15].

Involvement in medical procedures

The analysis of the GPs' application of minor technical procedures demonstrated a significant difference between Estonia and Finland. Even though the involvement in some technical procedures has increased in Estonia and decreased in Finland, the GPs in Finland still reported significantly greater involvement. The relatively easy access to hospital EDs and ambulance services in Estonia might be one reason of the low involvement of Estonian GPs in minor technical procedures compared to their Finnish colleagues. The organizational changes in Finnish health system have impacted the GPs' involvement in some minor technical procedures as well. During the last twenty years, small units of out-of-hours services have been closed and acute services have been transferred towards bigger acute centres [32]. This is probably a reason of a remarkable decrease in some procedures such as setting an intravenous infusion or strapping an ankle.

In Estonia, there might also be a lack of funding incentives, as these procedures are not additionally paid for like supplementary lab tests or investigations [15]. It is also possible that not all Estonian GPs have developed the skills to perform these procedures, as ambulatory surgery services are widely available elsewhere, even though in 1998 already 74\% of Estonian GPs had basic medical equipment for minor surgery [20]. There are also differences in organization of practices in Estonia and Finland which have a role in the different frequency in performing the medical procedures. Finnish GPs work in health centres together with a number of other health care staff, whereas Estonian GPs have mostly solo practices with one practice nurse. Moreover, the mean consultation time in Estonia was remarkably shorter than in Finland. Therefore, even the Estonian GPs have skills and equipment, they may not have enough human and time resources to perform minor surgery.

Additionally, some background factors could be related to the services profiles, like age and gender of GPs or the location of practice. These determinants were analysed extensively in 1993 [33] and 2012 [34]. Both in 1993 and 2012 it was found that GPs provide a broader range of services when they are located in a more rural area and hence located further away from the hospital. In 1993 there were no statistical differences for the GPs' involvement as the first contact to care related to age or gender, but women were less often conducted technical procedures. In 2012, it was found that women were more the first contact to care for a broader range of health problems than men, whereas they were still less involved in technical procedures. The higher proportion of women among the Estonian GPs, as well the increase of women in Finnish GPs during 1993-2012 might explain the lower involvement of Estonian GPs compared to the Finnish GPs as well to the decrease of Finnish GPs' involvement in technical procedures. Moreover, in 2012 the proportion of rural practices was higher in Finland than in Estonia, which may explain the differences in application of technical procedures as well. 
Põlluste, K., Kosunen, E., Koskela, T., Mattila, K.J., Schäfer, W.L.A., Boerma, W.G.W., Lember, M. Primary health care in transition: variations in service profiles of general practitioners in Estonia and in Finland between 1993 and 2012. Health Policy: 2018

An international comparison of GP services in Europe in 1993 demonstrated that the GPs in western countries had a much stronger role in first contact, the application of medical procedures, and prevention than GPs in eastern countries. It was suggested that more comprehensive general practice was associated with organisational aspects of PC, such as the gate-keeping system and selfemployment of GPs [3]. As demonstrated in our study, the implementation of the organizational changes together with the new training principles has significantly promoted the range of services provided by GPs in Estonia. Also, the results of this study show that a greater change in the range of services in the Estonian PC system which has undergone very rapid changes during a relatively short period in time. In Finland, where the modern PC system was introduced already in the beginning of 1970s, the transformation of the system has taken place over longer period, which is visible in a slower pace in the changes in GPs' services provided. These results are in line with those found in the international comparison of 28 countries [4]: As in most transitional countries, GPs in Estonia have broadened their range of services, but, as in other Western European countries, developments in Finland were less evident.

This cross-European study found that several national conditions were associated with the changes in GPs services [4]. The results of our study add more detailed insight into these associations. The comparison of two countries highlighted the relevance of the training and organizational aspects in the change of GPs service profiles, but did not confirm the association between the growth in health care expenditures and the breadth of the range of services found in cross-European study [4]. The results show that the importance of factors related to the changes could differ by country. Thus, the findings of this study could encourage other countries to conduct the similar analysis.

From the policy perspective, the breadth of the GPs services seems to be a good indicator to describe the progress of PC system as well the developments in other health care sector. Analysis of GPs services will provide an input for the development of training programmes of GPs [4] as well for other health professionals, but also for planning the PC services. The changes in the range of GP services might be related to the GPs job satisfaction, too, as demonstrated by Kalda et al (2000) [21]. A possible weakness of this study is the rather low response rate in 2012. In 1993, the response rate in Estonia was $62 \%$ and in Finland $42 \%$, but in 2012 the response rates were remarkably lower remaining below the median response rate (30\%) of QUALICOPC study [35]. Still, in both countries the age and gender structure of the respondents corresponded to that of practicing GPs; thus, the possible ageand gender-related features of the service profiles could be excluded. The common problem regarding low response rate in recruitment of GPs into research has been reported by other authors as well [36]. The common factors related to the low response rate in QUALICOPC study were higher survey load and strength of PC system, which are typical of both countries; additionally, the small number of entire study population and remuneration mechanism of GPs may explain the low response rate in Estonia as well [35].

\section{Conclusion}

Today, in the European context the PC structures in both Estonia and in Finland are defined as relatively strong; the PC policies and regulations are defined and combined with good financial coverage and resources, as well as adequate primary care workforce conditions [1]. Increased similarities in the PC structures are also visible in the decreased differences between the countries related to the involvement of GPs in patient care. The comparison of GP services in Estonia and in Finland showed that both countries underwent changes in the organisation of PC, which have formed the work of GPs as well. Partly opposite changes have made the services provided by GPs more similar. Still, there are large differences in services provided, possibly resulting from differences in the organisation of health services, availability of other health services, training and continuous medical education of doctors, as well as patients' preferences. 
Põlluste, K., Kosunen, E., Koskela, T., Mattila, K.J., Schäfer, W.L.A., Boerma, W.G.W., Lember, M. Primary health care in transition: variations in service profiles of general practitioners in Estonia and in Finland between 1993 and 2012. Health Policy: 2018

\section{Acknowledgements}

The study is part of the European QUALICOPC study, which is coordinated by NIVEL and co-funded by the European Commission under the Seventh Framework Program FP7/ 2007-2013. Grant 242141.

\section{References}

[1] D.S. Kringos, W. Boerma, Y. Bourgueil, et al. The strength of primary care in Europe: an international comparative study British Journal of General Practice, 63 (2013), pp. e742-750 [2] P.P. Groenewegen, P. Dourgnon, S. Greß, A. Jurgutis, S. Willems Strengthening weak primary care systems: steps towards stronger primary care in selected Western and Eastern European countries Health Policy, 113 (2013), pp. 170-179

[3] W.G.W. Boerma, J. van der Zee, D.M. Fleming, et al.Service profiles of general practitioners in Europe British Journal of General Practice, 47 (1997), pp. 481-486

[4] W.L. Schäfer, W.G. Boerma, P. Spreeuwenberg, F.G. Schellevis, P.P. Groenewegen Two decades of change in European general practice service profiles: conditions associated with the developments in 28 countries between 1993 and 2012 Scandinavian Journal of Primary Health Care (34) (2016), pp. 97-110

[5] L. Vuorenkoski, P. Mladovsky, E. Mossialos Finland: health system review Health Systems in Transition, 10 (2008), pp. 1-168

[6] T. Lai, T. Habicht, K. Kahur, M. Reinap, R. Kiivet, et al. Estonia: health system review Health Systems in Transition, 15 (2013), pp. 1-196

[7] M. Lember, E. Kosunen, W. Boerma Task profiles of district doctors in Estonia and general practitioners in Finland Scandinavian Journal of Primary Health Care, 16 (1998), pp. 56-62

[8] Statistics Estonia. 2015. Available at http://www.stat.ee/ (Accessed 07 October 2018).

[9] Statistics Finland, 2015. Available at http://www.tilastokeskus.fi (Accessed 07 October 2018).

[10] European Health for All database (HFA-DB). Available at: http://www.euro.who.int/en/dataand-evidence/databases/european-health-for-all-database-hfa-db (Accessed 07 October 2018).

[11] T. Hermanson, S. Aro, C.L. Bennett Finland's health care system. Universal access to health care in a capitalistic democracy The Journal of the American Medical Association, 271 (1994), pp. 1957-1962

[12] J. Halonen, E. Kumpusalo, P. Kekki, et al. Specialist education in general practice in Finland (in Finnish) Journal of the Finnish Medical Association, 56 (2001), pp. 433-436

[13] M. Lember Family practice training in Estonia Family Medicine, 28 (1996), pp. 282-286

[14] H.I. Maaroos Family Medicine as a model of transition from academic Medicine to academic health care: Estonia's experience Croatian Medical Journal, 45 (2004), pp. 563-566

[15] K. Põlluste, V. Kasiulevičius, S. Veide, D.S. Kringos, W. Boerma, M. Lember Primary care in Baltic countries: a comparison of progress and present systems Health Policy, 109 (2013), pp. $122-$ 130

[16] H.I. Maaroos, M. Lember Specialist training of family physicians in non-UEMO countries: an Estonian experience European Journal of General Practice, 13 (2007), pp. 246-247

[17] K. Põlluste, R. Kalda, M. Lember Primary health care system in transition: patients' experience International Journal for Quality in Health Care, 2000 (12) (2000), pp. 503-509

[18] K. Põlluste, R. Kalda, M. Lember Evaluation of primary health care reform in Estonia from patients' perspective: acceptability and satisfaction Croatian Medical Journal, 45 (2004), pp. 582 587

[19] K. Põlluste, R. Kallikorm, K. Meiesaar, M. Lember Use of general practice and rheumatology outpatient services in rheumatoid arthritis Family Practice, 29 (2012), pp. 433-440 
Põlluste, K., Kosunen, E., Koskela, T., Mattila, K.J., Schäfer, W.L.A., Boerma, W.G.W., Lember, M. Primary health care in transition: variations in service profiles of general practitioners in Estonia and in Finland between 1993 and 2012. Health Policy: 2018

[20] R. Kalda, M. Lember Setting national standards for practice equipment. Presence of practice equipment in Estonian practices before and after introduction of guidelines with feedback International Journal for Quality in Health Care, 12 (2000), pp. 59-63

[21] R. Kalda, H.I. Maaroos, M. Lember Motivation and satisfaction among Estonian family doctors working in different settings European Journal of General Practice, 6 (2000), pp. 15-19

[22] Finnish Medical Association Physicians in Finland. Statistics on physicians and the health care system (2014) (Accessed 07 October 2018)

http://www.laakariliitto.fi/site/assets/files/1268/laakarit_suomessa_2014.pdf

[23] Ministry of social affairs and health Occupational health care (Accessed 07 October 2018) https://stm.fi/en/occupational-health-care

[24] M. Sumanen, T. Aine, H. Halila, et al. Where have all the GPs gone - where will they go?

Study of Finnish GPs BMC Family Practice, 13 (2012), pp. 121-127, 10.1186/1471-2296-13-121

[25] R. Raivio, J. Jääskeläinen, D. Holmberg-Marttila, K. Mattila Decreasing trends in patient satisfaction, accessibility and continuity of care in Finnish primary health care BMC Family Practice, 15 (2014), p. 98, 10.1186/1471-2296-15-98

[26] W.L.A. Schäfer, W.G.W. Boerma, D.S. Kringos, et al. Study protocol: QUALICOPC, a multicountry study evaluating quality, costs and equity in primary care BMC Family Practice, 12 (2011), p. $115,10.1186 / 1471-2296-12-115$

[27] W.L.A. Schäfer, W.G.W. Boerma, D.S. Kringos, et al. Measures of quality, costs and equity in primary health care: instruments developed to analyse and compare primary health care in 35 countries Quality in Primary Care, 21 (2013), pp. 67-79

[28] I. Liseckiene, W.G. Boerma, Z. Milasauskine, L. Valius, I. Miseviciene, P.P. Groenewegen Primary care in post-communist country 10 years later. Comparison of service profiles of Lithuanian primary care physicians in 1994 and GPs in 2004 Health Policy (83) (2007), pp. 105-113 [29] M. Akman, S. Sakarya, M. Sargin, et al. Changes in primary care provision in Turkey: a comparison of 1993 and 2012 Health Policy (121) (2017), pp. 197-206

[30] P. Ööpik, A. Aluoja, R. Kalda, H.I. Maaroos Family doctors' problems and motivating factors in management of depression BMC Family Practice, 7 (2006), p. 64

[31] K. Põlluste, R. Kalda, M. Lember Accessibility and use of health services among older Estonian population Central European Journal of Public Health, 17 (2009), pp. 64-70

[32] M. Kangas, J. Vänskä Terveyskeskuspäivystys keskittyy ja vähenee [Out-of-hours service in health centres will be centred and decreased] Journal of Finnish Medical Association, 61 (2006), pp. 2507-2510

[33] W.G.W. Boerma Profiles of general practice in Europe. An international study of variation in the tasks of general practitioners NIVEL, Utrecht (2003) (Accessed 07 October 2018) https://www.nivel.nl/sites/default/files/bestanden/profiles-of-general-practice-in-europe.pdf [34] W.L.A. Schäfer Primary care in 34 countries: perspectives of general practitioners and their patients NIVEL, Utrecht (2016) (Accessed 07 October 2018)

https://www.nivel.nl/sites/default/files/bestanden/Proefschrift_Primary_care_34_countries_Schafer. pdf

[35] P.P. Groenewegen, S. Greß, W. Schäfer General practitioners' participation in a large, multicountry combined general practitioner-patient survey: recruitment procedures and participation rate International Journal of Family Medicine, 2016 (2016), p. 4929432, 10.1155/2016/4929432 [36] A. Parkinson, L. Jorm, K.A. Douglas, et al. Recruiting general practitioners for surveys: reflections on the difficulties and some lessons learned Australian Journal of Primary Health, 21 (2) (2015), pp. 254-258, 10.1071/PY13129 
Põlluste, K., Kosunen, E., Koskela, T., Mattila, K.J., Schäfer, W.L.A., Boerma, W.G.W., Lember, M.

Primary health care in transition: variations in service profiles of general practitioners in Estonia and in Finland between 1993 and 2012. Health Policy: 2018

Tables and figures

Table 1. Demographic characteristics, health care resources and utilisation in Estonia and in Finland, 1993 and 2012 [[10], [11], [12]].

\begin{tabular}{|c|c|c|c|c|}
\hline \multirow{2}{*}{ Indicators } & \multicolumn{2}{|l|}{ Estonia } & \multicolumn{2}{|l|}{ Finland } \\
\hline & 1993 & 2012 & 1993 & 2012 \\
\hline \multicolumn{5}{|c|}{ Demographic characteristics (Statistics Estonia [19], Statistics Finland [20]) } \\
\hline Mid-year population & $1,494,128$ & $1,322,696$ & $5,066,447$ & $5,413,970$ \\
\hline$\%$ of population aged $0-14$ years & 21.8 & 15.4 & 19.1 & 16.4 \\
\hline$\%$ of population aged $65+$ years & 12.2 & 17.9 & 13.9 & 18.8 \\
\hline Life expectancy at birth (years), males & 62.3 & 71.4 & 72.1 & 77.5 \\
\hline Life expectancy at birth (years), females & 73.8 & 81.2 & 79.5 & 83.8 \\
\hline \multicolumn{5}{|l|}{ Health care resources (HFA-DB) [21] } \\
\hline Total health expenditure as \% of GDP & $5.9^{1}$ & 5.9 & 8.2 & 9.1 \\
\hline Total health expenditures per capita (in PPP \$) & $513^{1}$ & 1393 & 1388 & 3498 \\
\hline Acute hospital beds (per 100,000 population) & 755.0 & 385.1 & 311.4 & 325.1 \\
\hline Nursing and elderly home beds (per 100,000 population) & $426.9^{2}$ & 699.5 & $553.7^{3}$ & 1116.3 \\
\hline Physicians (per 100,000 population) & 320.7 & 328.3 & $219.1^{4}$ & 300.7 \\
\hline GPs (per 100,000 population) & N/A & 74.5 & 60.2 & 69.3 \\
\hline Nurses (per 100,000 population) & 700.7 & 646.0 & $954.6^{5}$ & 1454.2 \\
\hline$\%$ of nurses working in hospital & $\mathrm{N} / \mathrm{A}$ & $73.1^{6}$ & $\mathrm{~N} / \mathrm{A}$ & $66.1^{7}$ \\
\hline \multicolumn{5}{|l|}{ Health care utilisation (HFA-DB) [21] } \\
\hline Outpatient contacts per person per year & 5.8 & 6.3 & 3.9 & 4.2 \\
\hline Average length of stay (days) in acute hospitals & 12.5 & 5.6 & 5.7 & 6.9 \\
\hline Acute care hospital discharges (per 100 population) & 18.0 & 15.6 & 22.8 & 16.9 \\
\hline
\end{tabular}

${ }^{1}$ This number refers to 1999.

2 This number refers to 1998.

${ }^{3}$ This number refers to 1996.

${ }^{4}$ This number refers to 1995.

${ }^{5}$ This number refers to 2000 .

${ }^{6}$ This number refers to 2010.

${ }^{7}$ This number refers to 2009. 
Põlluste, K., Kosunen, E., Koskela, T., Mattila, K.J., Schäfer, W.L.A., Boerma, W.G.W., Lember, M. Primary health care in transition: variations in service profiles of general practitioners in Estonia and in Finland between 1993 and 2012. Health Policy: 2018

Table 2. Basic characteristics ( \pm SD) of Estonian and Finnish PC doctors' work in 1993 and 2012.

\begin{tabular}{|l|l|l|l|l|}
\hline \multirow{2}{*}{ Characteristics of GPs' work } & \multicolumn{3}{l}{ Estonia } & \multicolumn{2}{l|}{ Finland } \\
\cline { 2 - 5 } & $\begin{array}{l}1993 \\
(\mathrm{n}=139)\end{array}$ & $\begin{array}{l}2012 \\
(\mathrm{n}=129)\end{array}$ & $\begin{array}{l}1993 \\
(\mathrm{n}=239)\end{array}$ & $\begin{array}{l}2012 \\
(\mathrm{n}=288)\end{array}$ \\
\hline Regular working hours/week & $37 \pm 6$ & $38 \pm 10$ & $38 \pm 4$ & $35 \pm 8^{*}$ \\
\hline of which, direct patient care & - & $30 \pm 9$ & - & $26 \pm 8$ \\
\hline Consultations/day & $16 \pm 5$ & $22 \pm 9^{*}$ & $19 \pm 8$ & $13 \pm 5^{*}$ \\
\hline Home visits/week & $16 \pm 7$ & $2 \pm 2^{*}$ & $2 \pm 8$ & $0.6 \pm 5^{*}$ \\
\hline Phone consultations/day & $4 \pm 3$ & $12 \pm 9^{*}$ & $6 \pm 3$ & $6 \pm 3^{*}$ \\
\hline E-mail consultations/day & - & $2 \pm 3$ & - & $(0,3)$ \\
\hline $\begin{array}{l}\text { Consultation time (min.) when using } \\
\text { appointments }\end{array}$ & $15 \pm 4$ & $16 \pm 4$ & $18 \pm 4$ & $23 \pm 6^{*}$ \\
\hline
\end{tabular}

*Indicates significant changes between years at $p<0.05$.

Fig. 1. Percentage of GPs reporting almost always or usually to act as the doctor of first contact for their patients for the following problems in Estonia and in Finland in 1993 and in 2012.

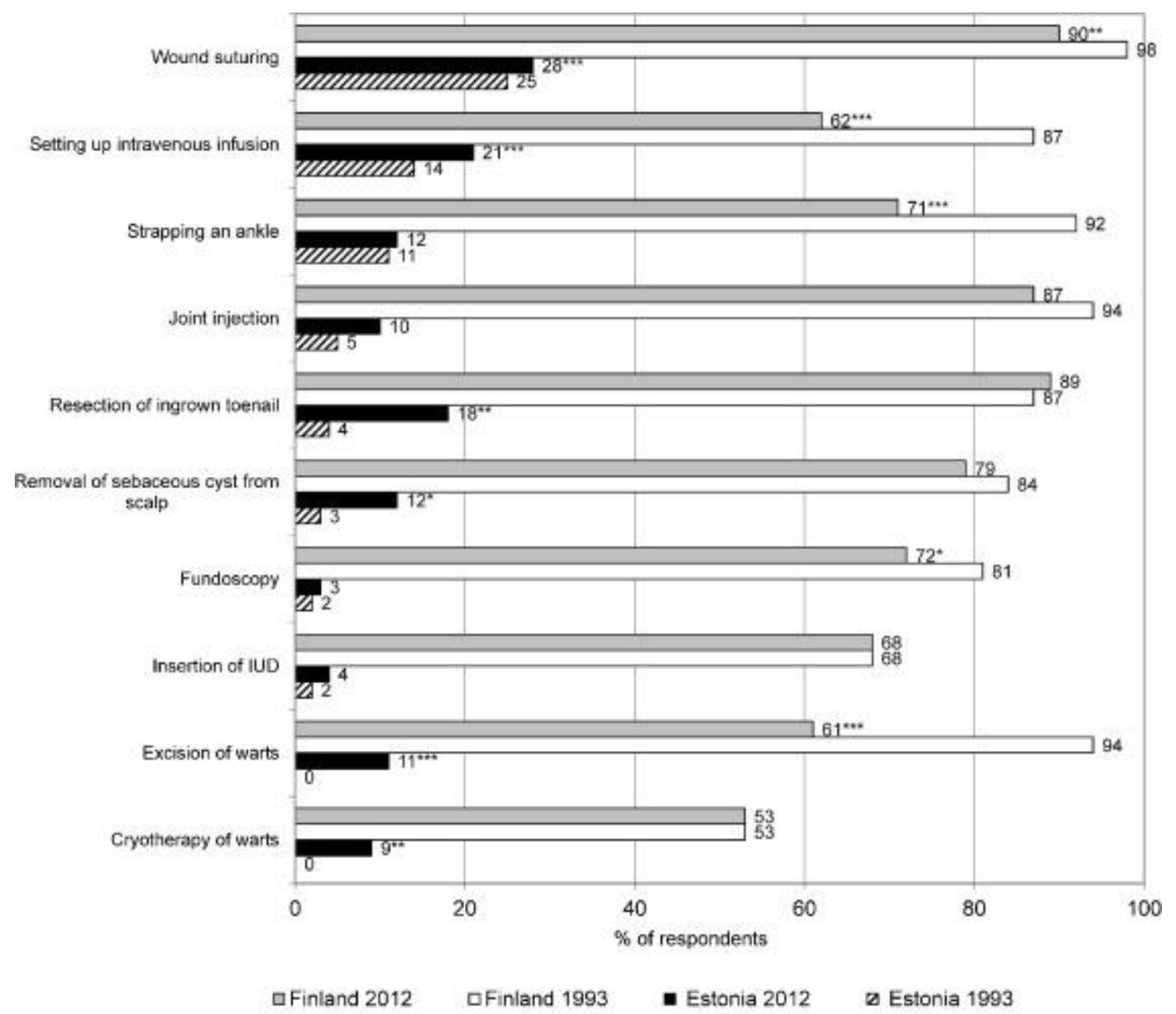

Significant differences between 1993 and 2012: "p<0.05; " $" p<0,01 ; \cdots p<0.001$ 
Põlluste, K., Kosunen, E., Koskela, T., Mattila, K.J., Schäfer, W.L.A., Boerma, W.G.W., Lember, M.

Primary health care in transition: variations in service profiles of general practitioners in Estonia and in Finland between 1993 and 2012. Health Policy: 2018

Fig. 2. Percentage of GPs reporting to perform the following procedures by themselves almost always or usually in 1993 and 2012, Estonia and Finland.



aFinland 2012 口Finland 1993 -Estonia 2012 aEstonia 1993 